\title{
Sweetening the Transition in EU Sugar Preferences: The Case of Fiji
}

\author{
Theodore Levantis, ${ }^{1}$ Frank Jotzo ${ }^{2}$ and Vivek Tulpulé ${ }^{1}$ \\ ${ }^{1}$ Australian Bureau of Agricultural and Resource Economics, and \\ ${ }^{2}$ Australian National University
}

\section{INTRODUCTION}

(b)

RANTING developing countries preferential access to otherwise protected developed country markets has been seen as a strategy to help their development by increasing the value of their exports, promoting industrialisation and ultimately accelerating economic growth. This system of preferential access has been used by the European Union as a way of extending aid to a number of former colonies. But trade preference schemes have been criticised for their effects on world commodity markets, as well as their impact on the developing countries that they are supposed to assist (Topp, 2001; and Oxfam, 2002).

Where trade preferences are given for particular products or industries, artificial comparative advantage is generated and economic activity concentrates in these sheltered activities. Resources are thus diverted from where there may be natural comparative advantage. In the longer term, this can stifle innovation and depress productivity growth, and, ultimately, part of the rents created by abnormally high prices received for the products in question get dissipated in inefficient production processes. Furthermore, trade preferences disadvantage producers in countries that do not receive them, as they lose out on market access and face depressed world market prices. This problem extends to low-cost producers in a number of developing and least developed countries. Perhaps of greatest concern is the dependence of beneficiary industries on trade preferences and their vulnerability to the consequences of any future change in trade preference policy.

The European Union's (EU) preferential arrangements for exports of bananas, sugar, rum and beef from the group of 76 African, Caribbean and Pacific

The authors wish to acknowledge helpful comments made by Joan Hird of the Department of Foreign Affairs and Trade, Australia, and Ivan Roberts, Vernon Topp and Richard Perry of ABARE. The authors would also like to acknowledge the comments of an anonymous referee. 


\section{THEODORE LEVANTIS, FRANK JOTZO AND VIVEK TULPULÉ}

countries - collectively referred to as ACP countries - can be criticised on these grounds. There is increasing support within the European Union for the view that these trade preference schemes should be reformed or even abolished, and replaced by more effective aid and support for better integration of the ACP countries in the world economy (European Commission, 2002).

This paper focuses on preferential access to EU sugar markets for ACP countries. If and when trade preferences are removed, these countries will face challenges of adjustment, but also opportunities to make their economies more dynamic. Some background and key data on the ACP sugar preference scheme and its beneficiaries are presented, and the argument is laid out for diverting the funds spent on paying inflated prices for sugar into building a stronger social and economic base. The mechanism explored in this paper for achieving this is investment in infrastructure. But the arguments could easily be extended to building capacity in governance, law and order, education or health.

Fiji is used as a case study for testing quantitatively the implications of alternatives to trade preference schemes. Fiji is the second largest recipient of income transfers from the EU through preferential access for sugar exports, and these income transfers are significant for the Fijian economy, amounting to 2.9 per cent of GDP in 2001.

\section{EU SUGAR SUPPORT AND TRADE PREFERENCES}

\section{a. The EU Sugar Regime}

The European Union has a highly regulated market system for sugar that provides price support for domestic producers, as well as for preferential imports (Sheales et al., 1999). The internal support price ('intervention price') for raw sugar has been 523.70 euro a ton since 1995-96, between two and three times the world market price (Figure 1).

The intervention price is maintained primarily through import restrictions and export subsidies. The volume of production that receives price support is limited by a quota system. Under this system, a base quantity of sugar, called the 'A' quota, receives the intervention price. A further quantity, called the ' $B$ ' quota receives a lower level of price support. Production beyond the combined A and B quotas, called ' $\mathrm{C}$ ' sugar, receives no price support and must be exported at world market prices. Levies are charged on in-quota sugar production to cover the budget cost of disposal of surplus quota sugar on world markets. These levies underpin the claim that the EU sugar regime is 'self-financing' - it is financed predominantly through higher consumer prices, rather than through taxes. The total cost of exporting surplus sugar from the European Union has been estimated at 1.6 billion euro for the year 2000 (Court of Auditors, 2001). 
FIGURE 1

Sugar World Market Price and the EU Guaranteed Price

World market prices and ACP guaranteed price for sugar

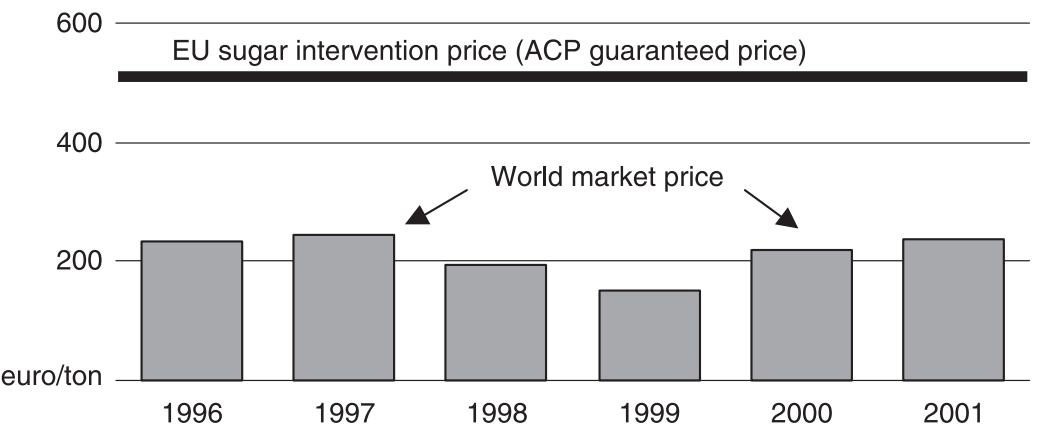

Notes:

World market price: Price of London CIF price for no. 7 (raw sugar in bulk), converted from US\$ to euro.

Source: Licht (2002); EU intervention price, equal to the guaranteed price paid for preferential ACP imports: 523.70 euro per ton of raw sugar.

Additional funding is provided for export subsidies for a quantity of sugar equal to the EU's preferential imports. These funds are characterised by the EU as development aid as the rents on these quantities of sugar go to exporters in ACP countries, rather than to EU farmers. Sugar preferences could be abolished and replaced with payments for real development assistance without disturbing the EU budget or the support arrangements for EU sugar farmers.

The EU has not made any reduction commitments under WTO agreements in respect of subsidised exports of ACP sugar. For example, the European Union notified export subsidies of 373 million euro for the year 2000-01 (WTO, 2002), less than half the total amount if ACP sugar had been included in the calculations. Export subsidies for ACP sugar are also outside the limits placed on expenditure for the Common Agricultural Policy (CAP) agreed on by the EU internally.

An overall liberalisation of EU sugar markets could yield more substantial benefits than abolishing trade preferences alone, both in terms of efficiency gains within Europe and for sugar exporters globally. The current regime results in economic inefficiencies due to rigid allocation of production quota and subsidised exports of sugar that is produced at costs higher than the world price (Bureau et al., 2001). It also tends to depress and destabilise world sugar prices, and market access is denied for producers in countries that do not enjoy preferential treatment, including the large majority of sugar producers in developing countries. Developing countries as a group contributed 65 per cent of global sugar exports in 2001, while exports to the EU under preferential treatment accounted for just 4 per cent (FAOSTAT database). 


\section{THEODORE LEVANTIS, FRANK JOTZO AND VIVEK TULPULÉ}

\section{b. EU Sugar Trade Preferences for ACP Countries}

Preferential access to European markets for producers in ACP countries was designed to compensate for bilateral trade preferences lost by former colonies of the United Kingdom, France, Italy, Belgium and the Netherlands when the European Common Market was formed (Harris et al., 1978). The provisions for sugar trade are defined in the $1975 \mathrm{ACP} / \mathrm{EU}$ Sugar Protocol; these arrangements are part of a wider set of EU-ACP agreements, first under the Lomé Convention, then the Cotonou Agreement.

The Sugar Protocol states that 'the [European] Community undertakes for an indefinite period to purchase and import, at guaranteed prices, specific quantities of cane sugar, raw or white, which originate in the ACP states'. The price for sugar imported into the EU under these quotas has been equal to the EU intervention price for raw sugar, that is, 523.70 euro per tonne. The EU internal price, upheld by import barriers and production quotas, has been even higher than the intervention price. The system provides no incentive for ACP countries to develop sugar processing industries, as processed sugar exported to the European Union would fetch the same guaranteed price as raw sugar.

In addition to the quotas under the Sugar Protocol, since 1995 the EU has imported sugar at slightly lower prices under the Special Preferential Sugar (SPS) agreement. The total quota of around 1.6 million tons of white sugar equivalent consists of just under 1.3 million tons under the Sugar Protocol, attracting full EU sugar prices, with the rest accounted for by SPS allocations. These SPS allocations receive prices around 5 per cent lower than the full EU sugar prices, and have favoured Ivory Coast, Swaziland, Malawi and Zimbabwe. India also has a (relatively small) quota for preferential sugar exports. The SPS quotas are not guaranteed and have tended to decrease as sugar imports under the 'Everything But Arms' initiative have increased.

The extra revenue accruing to each ACP country from the preferential treatment - which amounts to an income transfer, or economic rent - can be calculated by multiplying the quota quantities by the price differential between the market price and the internal EU guaranteed prices (Table 1). The total income transfer from the EU to ACP countries arising out of the EU sugar trade preferences amounted to around 450 million euro in 2001. In years where the differential between the EU guaranteed price and the world market price was larger, as was the case from 1998-2000, the total subsidy to ACP countries was greater than that amount.

The quota and associated rents are distributed very unevenly between ACP countries. The five largest of the 16 beneficiary countries receive almost 80 per cent of income transferred from the European Union. Mauritius alone accounts for over one-third of total extra revenue. The rents are significant on a per capita basis and as a share of GDP for most of the Caribbean and Pacific countries, but 
TABLE 1

Sugar Production and Income Transfers from Preferential Access to EU Markets, ACP Countries 2001

\begin{tabular}{|c|c|c|c|c|c|}
\hline & \multicolumn{2}{|c|}{$\begin{array}{l}\text { EU Import Quota } \\
\text { (Sugar Protocol quotas plus } \\
\text { SPS basic allocations) }\end{array}$} & \multicolumn{3}{|c|}{$\begin{array}{l}\text { Income Transfer from the EU } \\
\text { from Sugar Trade Preferences }\end{array}$} \\
\hline & $\begin{array}{l}\text { Tons (White } \\
\text { sugar } \\
\text { equivalent) }\end{array}$ & $\begin{array}{l}\text { Quota as a } \\
\text { Share of Total } \\
\text { Sugar Exports } \\
(\text { Per cent })^{\mathrm{b}}\end{array}$ & $\begin{array}{l}\text { Euro } \\
\text { Million }\end{array}$ & $\begin{array}{l}\text { Euro } \\
\text { Per Capita }\end{array}$ & $\begin{array}{l}\text { Per Cent } \\
\text { of } G D P^{\mathrm{c}}\end{array}$ \\
\hline Mauritius & 580.9 & $>100$ & 163.1 & 137.5 & 4.0 \\
\hline Fiji & 195.6 & 74 & 54.9 & 67.6 & $2.9^{\mathrm{d}}$ \\
\hline Guyana & 188.6 & 78 & 52.9 & 69.6 & 8.1 \\
\hline Swaziland & 169.4 & 59 & 46.9 & 44.9 & 3.4 \\
\hline Jamaica & 140.4 & 94 & 39.4 & 15.0 & 0.6 \\
\hline Barbados & 59.5 & $>100$ & 16.7 & 62.6 & 0.7 \\
\hline Zimbabwe & 60.8 & 36 & 16.5 & 1.3 & 0.2 \\
\hline Trinidad and Tobago & 51.8 & 91 & 14.5 & 11.2 & 0.2 \\
\hline Belize & 47.7 & 52 & 13.4 & 55.8 & 1.8 \\
\hline Malawi & 34.6 & 63 & 9.5 & 0.9 & 0.6 \\
\hline Côte d'Ivoire & 22.1 & 72 & 6.0 & 0.4 & 0.1 \\
\hline Saint Kitts and Nevis & 18.4 & 89 & 5.2 & 126.3 & 1.8 \\
\hline Madagascar & 12.7 & $>100$ & 3.6 & 0.2 & 0.1 \\
\hline Congo & 12.1 & 26 & 3.4 & 0.1 & 0.1 \\
\hline Tanzania & 12.1 & 27 & 3.4 & 0.1 & 0.04 \\
\hline Zambia & 12.1 & 10 & 3.1 & 0.3 & 0.1 \\
\hline Total & 1,619 & 73 & 452.5 & 2.9 & 0.7 \\
\hline
\end{tabular}

Notes:

a Preferential sugar import quotas and SPS basic allocation.

b Percentages greater than 100 imply that the quota was not filled. Statistical discrepancies are possible due to conversion from raw sugar to white sugar equivalent weights.

${ }^{c}$ GDP data (not PPP adjusted) for the year 2000.

d GDP data for year 2001 based on Fiji's national accounts.

Calculation based on a world market price of 238.78 euro per ton (2001 average price of London CIF price for no. 7 raw sugar in bulk), a preferential sugar price of 523.70 euro per ton, and a minimum purchase price under special preferential arrangements of 496.80 euro per ton.

Sources: Licht (2002), CAP monitor, FAOSTAT database, World Development Indicators (World Bank, 2002b).

do not contribute much to the economies of the majority of African countries covered by the scheme. A number of African ACP countries that produce sugar do not receive any EU sugar trade preferences.

The group of ACP countries is highly heterogeneous and GDP per capita varies considerably amongst ACP countries ranging from around US\$500 for Tanzania in purchasing power parity (PPP) adjusted prices in 2000, to over US\$15,000 for Barbados (Table 2). The contribution of agriculture in the economy varies from 58.0 per cent for Congo and 45.1 per cent for Tanzania to under 4 per cent for Trinidad and Tobago and Saint Kitts and Nevis (Table 2). Moreover, there is 


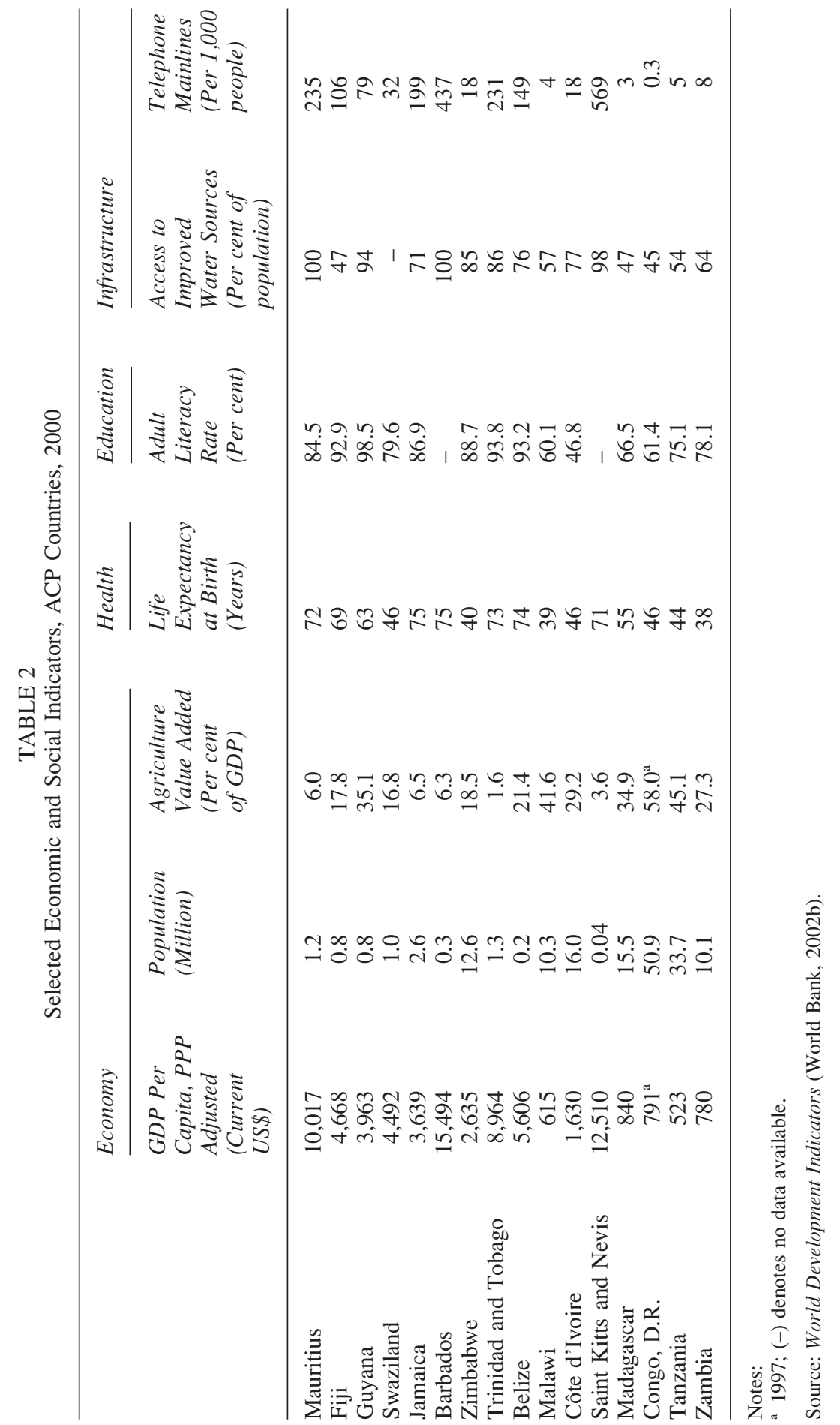


FIGURE 2

Relationship Between EU Sugar Income Transfers and Per Capita Income

The relationship between EU sugar income transfers and per capita national income $(2000 / 2001)$

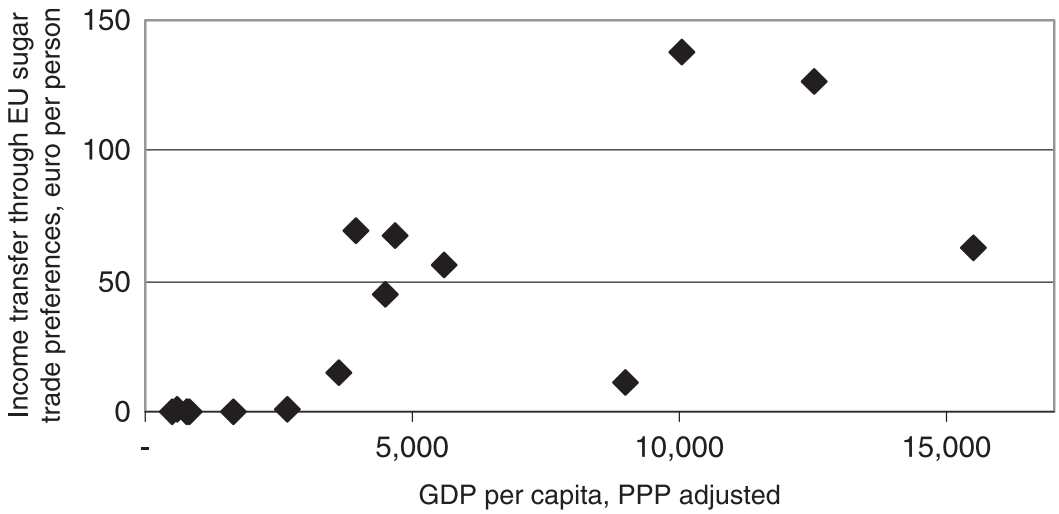

Note:

ACP countries with EU sugar preferences, 2000/2001.

Sources: see footnotes to Tables 1 and 2 .

great disparity in health and education indicators across the ACP countries and the state of infrastructure development also varies considerably (Table 2).

But the relationship between the size of income transfer under the sugar preferences and the per capita income of ACP countries is positive, that is, transfers through these preferences are skewed in favour of higher-income countries (Figure 2). For example, Mauritius has the highest quota allocation yet has the third highest per capita income and amongst the highest indicators for health, education and infrastructure development. In contrast, Zambia, Tanzania, Congo and Madagascar have the smallest per capita quotas yet have particularly poor social and economic indicators. This is unlikely to be a causal relationship, as income transfers from sugar trade preferences are not large enough to explain these large differences in per capita incomes.

Analysis of the impact of sugar trade preferences on ACP countries is sparse in the recent published academic literature. Herrmann and Weiss (1995) conducted a welfare economic analysis for the ACP recipients of EU sugar trade preferences. In addition to the transfer payments through higher sugar prices, which for the period 1975-91 yields similar results for the distribution between countries as outlined in Table 1 for the year 2001, Herrmann and Weiss also quantified the benefits to ACP countries from lower variability of sugar prices. Depending on the assumed level of risk aversion, the benefits from more stable prices are estimated to amount to between 17 and 42 per cent of the transfers. Nevertheless, the study concluded that the Sugar Protocol leads to reduced global 


\section{THEODORE LEVANTIS, FRANK JOTZO AND VIVEK TULPULÉ}

welfare, and that aid through sugar preferences is an inferior instrument compared to targeted redistribution policies.

\section{c. Managing the Transition}

Some observers expect that the Sugar Protocol and with it the price premiums achieved for preferential ACP exports will not last indefinitely. This expectation arises in part from the European Union's 'Everything But Arms' (EBA) scheme, which grants least developed countries increasing tariff-free access to EU markets (Page and Hewitt, 2002). Sugar imports under the EBA are scheduled to be fully liberalised in 2009, which is likely to result in significantly increased sugar exports from least developed countries to Europe at world prices. With higher imports from least developed countries, the European Union may be less willing to continue paying premiums for imports from ACP countries.

If preferential trading arrangements for sugar with the European Union were to be abolished, there is likely to be considerable economic adjustment in some ACP countries. Faced with the world market price for sugar, a large number of producers in ACP countries would not be profitable given current costs of production. Under these conditions, the extent to which cane growers can continue to be viable will depend on reducing production costs via industry restructure and streamlining production and domestic distribution systems (see for example IMF, 2002).

In some countries, sugar production will remain unprofitable even with reform, revealing the underlying pattern of comparative advantage between countries. It would then be economically beneficial to reallocate productive resources away from sugar production to more productive uses, which may be in other agricultural commodities, manufacturing or even service industries such as tourism.

Many ACP countries are apprehensive about this transition process, especially where a significant share of their workforce is employed in the sugar sector. The European Union, having supported these countries through trade preferences for decades and therefore having played its part in the entrenchment of inefficient sugar production in ACP countries, is concerned that the transition is managed well (European Commission, 2002).

However, this transition process has already been happening in most ACP countries over the last two decades. With the quota and income transfer remaining relatively unchanged, the importance of sugar preferences in the ACP economies has generally declined and other industries for which there exists natural comparative advantage have emerged. Tourism is the world's most important traded commodity, and with most ACP countries enjoying strong comparative advantage in tourism there has been a strong shift toward tourism in most of these countries. 
In managing a transition from sugar preferences, the funds used to subsidise sugar could instead be diverted to investing in building the social and economic infrastructure of ACP countries. Investment priorities will differ markedly between countries - one size does not fit all. Providing more and better economic infrastructure such as transport networks and public utilities (power and energy supply networks, telecommunications, sewerage and waste disposal etc.) will improve medium- to long-term growth opportunities in ACP countries - some more than others. For the Fiji case study of this paper, the focus is on the provision of such physical infrastructure.

At the same time, investing in the education or healthcare system could greatly enhance long-term prospects for prosperity. The health and education situation is particularly dire in some of the African ACP countries, and targeting the money currently spent on sugar subsidies on issues such as AIDS prevention and treatment or basic education would benefit these countries in the longer term, by maintaining the labour force and building up skill levels, as well as providing direct humanitarian benefits.

\section{d. EU Economic Partnership Agreements}

In September 2002, the European Union and ACP countries began negotiations on a new framework of economic relations between the two groups of countries. The current preferential trade system has been extended until the end of 2007, after which it is to be replaced by 'Economic Partnership Agreements' (EPAs).

According to proposals by the European Union, the EPAs should be free trade agreements between ACP regional groups and the European Union. Guiding principles are to be the following (Bilal and Van Hove, 2002):

- Development: The agreements are to be oriented towards facilitating sustainable development and reducing poverty in ACP countries.

- Reciprocity: All trade restrictions between the parties are to be progressively removed, leading to a free trade area. This is in marked contrast to the current non-reciprocal arrangement. ACP countries would have to open their markets for EU exports in order to keep or attain preferential access to EU markets.

- Regionalism: The European Union sees increased regional integration within groups of ACP countries as a step toward greater integration in the world economy, and is planning agreements with ACP regional groups rather than individual countries.

- Differentiation: The EPAs are to include a strong component of special and differential treatment, taking into account differing circumstances and stages of development of ACP countries. 


\section{THEODORE LEVANTIS, FRANK JOTZO AND VIVEK TULPULÉ}

While these general principles hold some promise for ACP countries, there are risks involved. In particular, reciprocity of preferential access across a whole range of products will lead to trade diversion: some of the trade between non-EU and ACP countries will be diverted to the EU, and as a result new or additional distortions may be introduced to ACP economies.

It is also unclear how free trade agreements would be implemented in highly distorted EU markets such as sugar; if the current EU regime were to be fully extended to ACP countries, this could mean that the preferential trade quota would be turned into an EU-style production quota, with similar distortions as under the current system of trade preferences. Much will depend on whether there will be reform of the EU sugar regime. There has been a general trend away from price support as a mechanism of EU agricultural policy; however, replacing price support for sugar with direct subsidies would require significant budget outlays for the European Union, and the feasibility of such a move is therefore questionable.

\section{e. Investment for Economic Growth}

The question in the process of transition is whether aid funds should continue to be channelled to the sugar industry. The hypothesis here is that the income transfers implicit in trade preferences would deliver significantly better outcomes if invested in improving infrastructure, health or education in the recipient ACP countries. Functioning infrastructure is a basic underpinning of economic activity, enabling companies and individuals to do business effectively and efficiently. Infrastructure has thus been described as 'if not the engine, then the wheels of economic activity’ (World Bank, 1994).

There is a strong positive relationship between per capita income levels and infrastructure stocks across countries; and at the same time, a number of studies have shown very high rates of economic returns to public infrastructure provision (World Bank, 1994). The impact of additional investment is highest where there is the least amount of existing infrastructure. Empirical studies confirm that public infrastructure provision is generally subject to diminishing returns (for example, Démurger, 2001). Public infrastructure investment and private investment are complements. The growth-augmenting effect of public investment in infrastructure will be boosted if the investment is well targeted and attracts additional private investment. The complementary nature of public infrastructure and private sector investment has been shown empirically in a number of econometric studies - for example by Sanchez-Robles (1998) for a sample of developing countries, and in a classic study by Aschauer (1989) for the United States.

However, a prerequisite for success of public investment is that existing obstacles to private investment be removed. This can include making property rights more secure, lowering taxes on productive activities, making the regulatory 
framework more transparent and predictable, improving legal institutions, and so forth. Recent thinking in development economics has emphasised the importance of functioning institutions for markets and economic growth (World Bank, 2002a). The relevance of this for the ACP countries has been demonstrated by Lall et al. (2000), in a quantitative study of productive efficiency and its drivers in the Caribbean compared to North and Latin America. They find that in order to improve efficiency in Caribbean countries, private investment needs to be encouraged and government investment should focus on providing infrastructure.

\section{THE FIJI SUGAR INDUSTRY}

Fiji's sugar industry has benefited immensely from preferential access to the European market. Sugar has become by far the most important source of cash incomes for rural Fijians and in 2001 accounted for 7 per cent of GDP. Cane production comprised 30 per cent of output of the agriculture, fishing and forestry sector. Exports of sugar in 2001 accounted for 22 per cent of all merchandise exports, making sugar Fiji's second most important merchandise export after garments.

Since the mid-1990s, Fiji's sugar industry has been in steady decline. The primary cause has been uncertainty over land tenure for Fiji's sugar farmers. Most sugar farming has been undertaken on land leased from traditional land holders with leases controlled and allocated from a central authority on long-term arrangements. The bulk of these leases have been due for renewal late in the 1990s and in the first decade of the new millennium. There has been considerable concern amongst sugar farmers about whether leases would be renewed and under what conditions renewals would take place. To date, many leases have not been renewed with the land reverting back to traditional owners.

A second cause has been the uncertainty surrounding the continuation of the preferential access to European markets and the consequences of lower prices for Fiji's sugar exports. The uncertainty over land tenure and of future access to favourable prices has led to a pattern of minimal investment and declining productivity. Output of the sugar industry as a share of GDP is now almost half the level of the mid-1990s, and sugar exports as a share of total merchandise exports has fallen to just under half of the mid-1990s level of 37 per cent.

Fiji has a maximum quota access to the European market of 195,600 tons of sugar and access to the US market of 9,000 tons per annum. In general, Fiji produces in excess of this quota with the bulk of the balance sold at world market prices to South East Asian countries and with a small amount sold domestically. The world market value of Fiji's sugar exports in 2001 was 62.9 million euro (F\$128.1 million). However, with preferential market access to Europe and the United States, the value of exports was raised to 120.7 million euro (F\$245.9 


\section{THEODORE LEVANTIS, FRANK JOTZO AND VIVEK TULPULÉ}

million). The sugar subsidy provided to the Fiji sugar industry by European and US interests was therefore 57.8 million euro (F\$117.8 million). Of this, the Subsidy transfer from the EU amounted to 54.9 million euro (F\$111.8 million). The EU subsidy in 2001 is equivalent to 2.9 per cent of Fiji's GDP, and the total subsidy, including that from exports to the United States, is 3.1 per cent of GDP. Nearly half of the value-added attributed to sugar cane and sugar processing is financed by the subsidy transfer.

The magnitude of this subsidy transfer to Fiji's sugar industry has influenced considerably the structure of the Fiji economy. With a subsidy equivalent to 3.1 per cent of GDP directed to a single industry, resource allocation across sectors and the pattern of economic growth have been profoundly affected. It is also for this reason that Fiji's economy is so highly vulnerable to domestic and international factors affecting sugar. Any changes to this subsidy could have major effects on Fiji's sugar industry and the Fiji economy as a whole.

Importantly for Fiji, there has been a steady reduction of its reliance on this subsidy. Over the last two decades, the quota has remained unchanged therefore providing no basis for growth in the sugar industry and for economic growth in general. Over this time, the Fiji economy has successfully diversified and expanded, thereby leading to a steady decline in the importance of the subsidy and the sugar industry relative to GDP. Fiji's investment in a strong education system has helped facilitate sufficient flexibility in the economy to enable this diversification.

\section{QUANTIFYING THE EFFECTS FOR FIJI}

\section{a. Background to the Quantitative Analysis}

To gain a clearer understanding of the implications of the preferential arrangements for the Fiji economy, a number of scenarios are considered and tested quantitatively using ABARE's dynamic computable general equilibrium (CGE) model of the Fiji economy, FIJIGEM. ${ }^{1}$ Rather than to advocate any specific policy alternative, the principal purpose of these scenarios is to demonstrate the general thrust of this paper that aid in the form of a sugar subsidy is a suboptimal form of aid delivery.

FIJIGEM is built around a Walrasian general equilibrium framework and is a comprehensive depiction of the Fiji economy. There are 35 industries in the model, including a sugarcane production industry and a sugar processing

\footnotetext{
${ }^{1}$ FIJIGEM is a development of the inaugural version of the model funded by the Australian Centre for International Agricultural Research. A full description of the current version of the model is available on www.abareconomics.com.
} 
industry. The model incorporates the household sector, the government sector, the financial sector, the external sector and the production sector and incorporates a range of taxes. The labour market design is built around a Harris-Todaro framework which splits the labour market between rural and urban labour and depicts structural urban surplus labour. Equilibrium in the flow of labour between rural and urban areas is achieved when the wage able to be attained in rural areas equates with the expected urban wage taking into consideration the probability of not finding a formal sector job. In production, capital utilisation is a function of profitability, and investment in each industry responds to movements in capital utilisation rates. The methodology is to compare the growth path of the Fiji economy post the scenarios with the 'business as usual' reference case growth path. The reference case maps the path the Fiji economy would take in the absence of any changes to sugar policy. The difference between the post-scenario path and the reference case path for the various economic variables in the model represents the impact of the scenarios.

In all, four scenarios are tested. Scenario 1 tests the importance of the subsidy transfer from the EU by considering a removal of preferential access. The remaining scenarios consider alternative frameworks for delivering aid whereby the equivalent sugar subsidy is replaced by direct budgetary aid to the Fiji Government. In these scenarios, the aid is redirected to new government development programmes or is used to enhance existing programmes. Scenario 2 considers the option of using the aid monies to fund a reduction by one-third in income tax and tariff rates. Such a scenario is unlikely as it would require a major shift in policy thinking within Fiji, but represents an interesting exercise for comparing alternative possible functions of aid funds.

Investment in infrastructure is conjectured as an alternative way to spend the aid funds and this is tested in Scenarios 3 and 4. A number of empirical studies have examined the relationship between infrastructure and economic growth, and attempted to quantify it. Most studies focus on the stock of physical infrastructure (for example, number of phone lines and length of the road network), and most find a significant positive relationship between these variables and economic productivity and/or growth. The recent literature has also highlighted spillover effects between public infrastructure provision and private investment (Wang, 2002). From the empirical literature, the focus for Scenarios 3 and 4 is the effect of ongoing infrastructure expenditure on productivity and growth. Cross-country regression studies using these variables cannot account for differences in price levels and efficiency of infrastructure provision between countries, but several studies nevertheless have established significant positive relationships and the studies described in Table 3 are used to guide the development of Scenarios 3 and 4.

Applying the results from these studies to Fiji, allocating an extra 54.9 million euro a year (the value of EU sugar transfer payments to Fiji in 2001) to capital 
expenditure by government would raise the potential long-term annual per capita GDP growth rate by between 0.16 and 0.69 per cent. These growth gains can be presumed to arise through increased capital and labour productivity, as they represent longer-term improvements in growth potential. To take a conservative approach, for Scenarios 3 and 4 it is assumed that the productivity gains from redirecting 54.9 million euro per year in aid flows into public infrastructure will deliver annual gains in total factor productivity of 0.25 per cent.

For Scenario 3, the gains are assumed to be spread evenly throughout the economy. However, given that it is rural employment and incomes that will be most affected from the removal of a sugar subsidy, it may be considered that aid directed to infrastructure development ought to be biased toward rural development. Scenario 4 assumes such a rural bias whereby the productivity gain is adjusted so that half of the economy-wide productivity gain is attributable to gains in agricultural industries. This is up from 15 per cent in Scenario 3 where the distribution of the productivity gain is even.

In interpreting the results for these scenarios it is worth noting that any impact on the world price for sugar is not accounted for. If the trade preference scheme were to be abolished, then a small increase in world prices would be expected. This would, in part, offset the negative impact on the average sugar prices received by ACP countries. It has been estimated that removing distorting policies in sugar markets the world over could lead to an increase in the world market price for sugar of between 5 and 41 per cent, depending on the scenario chosen (Sheales et al., 1999).

\section{b. GDP Effects}

As would be expected with the removal of sugar subsidies worth 2.9 per cent of GDP the immediate impact in Scenario 1 is for a decline in economic activity (Figure 3). But with the substitution of factors toward other forms of production, the net impact on GDP of 1.1 per cent is significantly less than the amount of loss in transfer payments from the European Union. Whilst the loss of preferential access to European markets would imply short-term costs, Fiji would move onto a stronger growth path. However, the rise in the growth path is small relative to the size of the initial losses and after 10 years, real GDP will still be 0.4 per cent below the level that would have been achieved in the absence of any change. This suggests that many years may pass before losses from an uncompensated removal of preferences can be recouped. The two principal reasons for the higher growth path are: (i) factor resources are diverted to sectors of the economy with stronger growth prospects; and (ii) factor resources are diverted to sectors providing higher productivity growth. Growth in Fiji's sugar industry is constrained by the fixed volume quota for access to the European market. For this reason, growth in other sectors of the economy consistently outpaces growth in 


\section{THEODORE LEVANTIS, FRANK JOTZO AND VIVEK TULPULÉ}

sugar. Productivity growth in sugar production is constrained by a lack of investment due both to the lack of growth prospects in European markets and due to land tenure uncertainty.

Diverting the funds directed to the sugar subsidy into financing a reduction in Fiji's taxes and tariffs (Scenario 2), and therefore a reduction in the distortions associated with them, delivers a significant benefit to Fiji in terms of stimulating overall production. Under this scenario, the switch would deliver an initial rise in real GDP of 1.0 per cent compared to the base situation of continued sugar preferences, and would move Fiji onto a higher growth path (Figure 2). After 10 years, real GDP would be 1.7 per cent higher than what would otherwise have been the case. This is despite inherent weakness of the benefits of tax reform due to the high propensity in Fiji for purchases of imports - a consequence of Fiji's relatively narrow production base. For this reason, the increase in disposable income associated with the reforms of Scenario 2, and hence the increase in consumption, will translate into a significant increase in imports, detracting from the impetus to GDP provided by the aid transfer.

Among the scenarios tested here, Scenario 3 and Scenario 4 (investing in infrastructure) deliver easily the biggest long-term gains for Fiji in terms of real GDP (Figure 2). But replacing the sugar subsidy with aid to finance infrastructure development does not generate the same short-term benefits. This is because the tax reform modelled in Scenario 2 delivers large and immediate gains in economic efficiency that are not evident in Scenarios 3 and 4. On the expenditure side of GDP, increased expenditure on public investment in Scenarios 3 and 4 crowd out some private consumption and investment, with both of these falling in real terms. But the public investment delivers returns in terms of gains in productivity and this enables Fiji to move onto a much stronger growth path. After four years, the gains in real GDP under Scenario 3 exceed those under Scenario 2, and after 10 years real GDP is 3.0 per cent higher than otherwise, which is nearly double the gain compared to Scenario 2 .

For Scenario 4, with more of a focus on rural infrastructure development, the gains are approximately the same as in Scenario 3. However, if equity considerations are taken into account, Scenario 4 will deliver greater benefits to the community than Scenario 3 by concentrating benefits to the rural poor. There is no consideration paid to equity in the modelling.

\section{c. Trade Impacts}

A reduction in the terms of trade (reduced export prices relative to import prices) is the initial impact of removing sugar preferences and this leads to a real exchange rate depreciation under all four scenarios. The ensuing stimulus to non-sugar exports dampens the overall impact on exports of the decline in sugar exports that result from the loss of sugar preferences. But under all four 
FIGURE 3

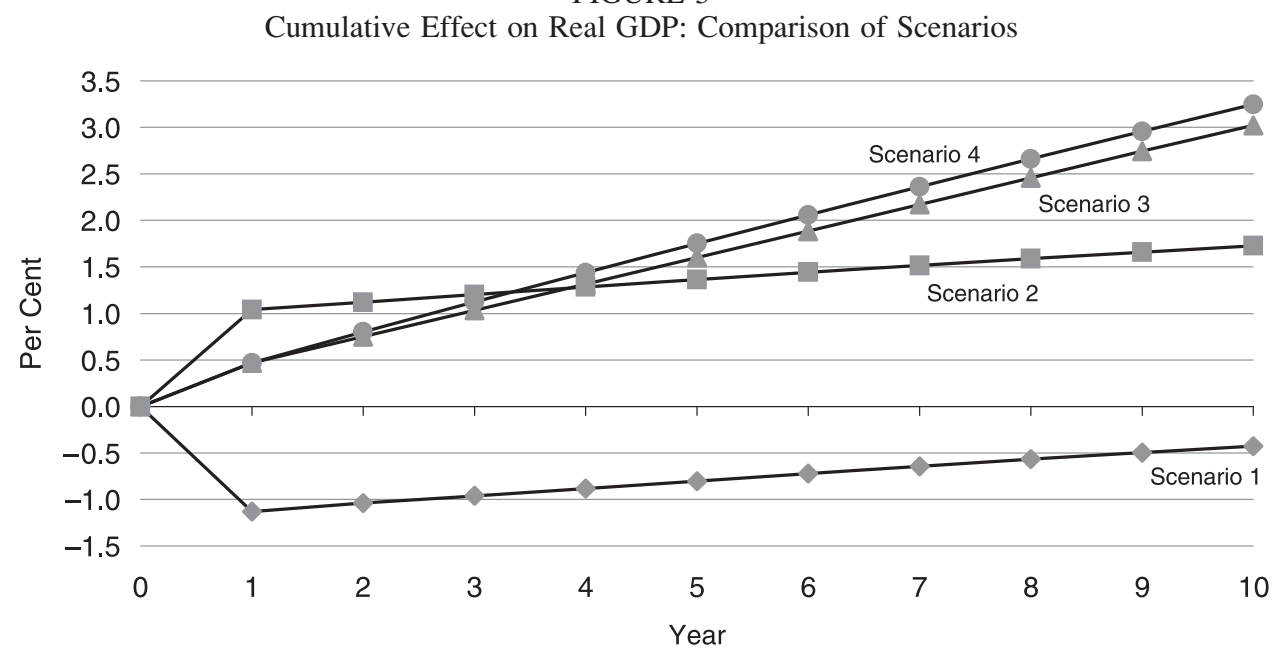

FIGURE 4

Cumulative Effect on Exports: Comparison of Scenarios

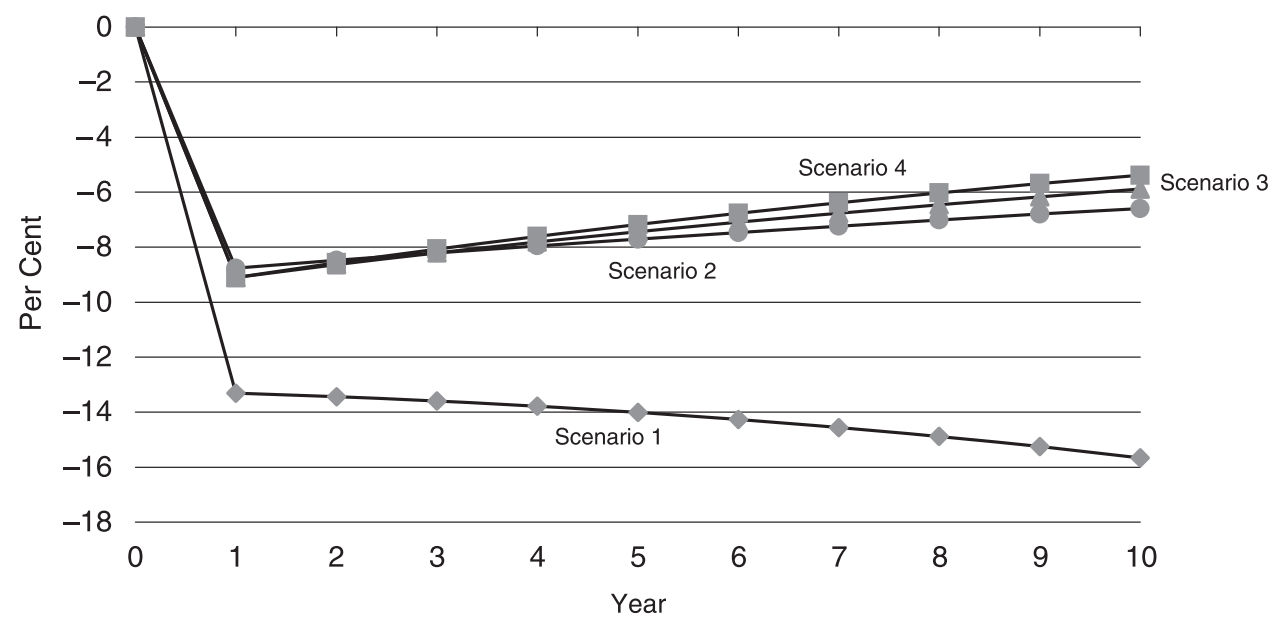

scenarios, overall exports still decline substantially (Figure 4). This is the inevitable consequence of removing a subsidy on an export industry. But Fiji does move on to a higher export growth path under Scenarios 2-4 due to the impetus provided by the alternative policy designs of these scenarios. However, after 10 years, exports will still be significantly below the levels that would have been attained if sugar preferences were to be continued.

C C Blackwell Publishing Ltd 2005 
910 THEODORE LEVANTIS, FRANK JOTZO AND VIVEK TULPULÉ

FIGURE 5

Cumulative Effect on Sugar Production: Comparison of Scenarios

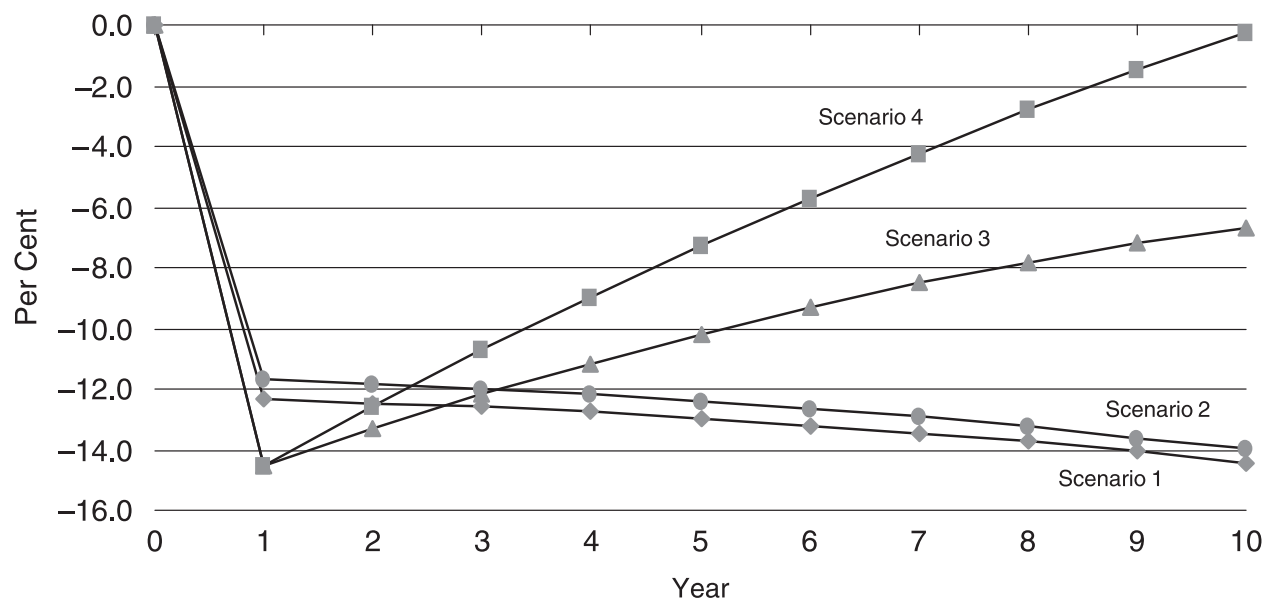

\section{d. Impacts on Sugar Production}

The immediate impact on sugar production of a removal of sugar preferences would be a decline of 12.4 per cent under Scenario 1 and a steady decline thereafter so that after 10 years, production would be 14.4 per cent lower (Figure 5). There would be little change to this pattern under Scenario 2 with reduced economic distortions delivering only a marginally improved outcome for sugar production.

Under Scenario 3, sugar production declines further initially compared to Scenarios 1 and 2 as factor resources are diverted into the building of infrastructure. However, the gains in productivity in the following years benefit the sugar industry and sugar production embarks on a growth path. After 10 years, the sugar industry would have contracted just 6.6 per cent compared to what would be the case if nothing changed. The increased rate of productivity gains in rural areas under Scenario 4 would result in sugar production after 10 years returning to the level that would otherwise have occurred. In other words, the productivity gains after 10 years will be sufficient to offset the loss in prices otherwise achieved under the scheme of sugar preferences. Beyond 10 years, sugar production will exceed the level achieved under protection.

\section{e. Employment Impacts}

Unskilled employment in rural areas declines sharply under all four scenarios (Figure 6). With the dominance of the sugar industry in rural employment, the unskilled employment curves of Figure 5 are similar in shape to the sugar output 
FIGURE 6

Cumulative Effect on Rural Unskilled Employment: Comparison of Scenarios

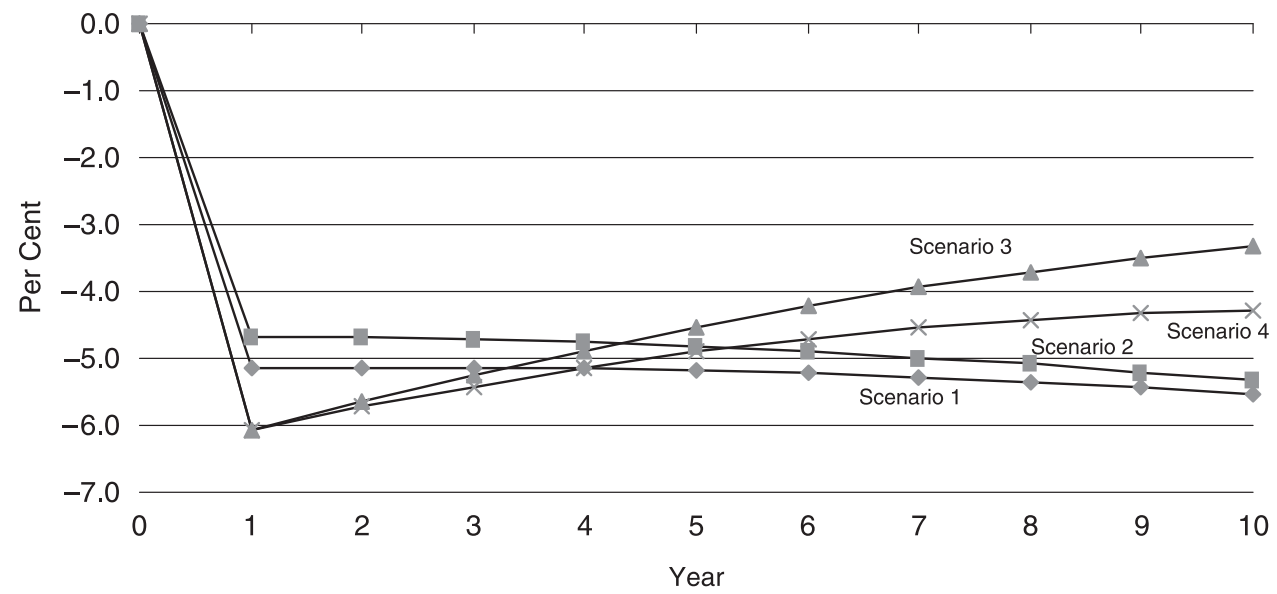

curves of Figure 4. The best-case scenario is Scenario 3 where after 10 years the loss in rural unskilled employment is 3.3 per cent. Despite the higher productivity growth in rural areas under Scenario 4, rural unskilled employment is weaker and remains 4.3 per cent below the baseline level after 10 years. The decline in Scenario 4 relative to Scenario 3 indicates that the stimulus to output and employment of gains in productivity in rural areas is insufficient to offset the shedding of excess labour as productivity rises.

In response to the fall in opportunities in rural areas relative to urban areas, there is a flow of migration of the unskilled workforce from rural to urban areas in each of the four scenarios. The displaced labour is then either absorbed into urban employment or is added to the pool of surplus labour. High urban wages encourage idle labour to seek employment in urban centres despite the existence of urban unemployment. Fiji's urban labour market is characterised by rigidities with regulated minimum wage rates above market-clearing levels. Due to these rigidities, there is limited scope for urban-based industries to absorb labour resources freed up from rural areas and this inevitably leads to an expansion in the pool of urban surplus labour.

For Scenario 1 there is only a small absorption of displaced rural labour into urban-based industries (Figure 7) and a significant jump in urban surplus labour (Figure 8). The stimulus provided to urban-based industries under the remaining scenarios, including the stimulus provided to industries benefiting from the boost in public investment expenditure, enables a greater rate of absorption of displaced labour. Under Scenario 3, there is a reduced rate of rural-to-urban migration over time compared to Scenario 4 which ultimately leads to a better outcome for urban surplus labour. 


\section{THEODORE LEVANTIS, FRANK JOTZO AND VIVEK TULPULÉ}

FIGURE 7

Cumulative Effect on Urban Unskilled Employment: Comparison of Scenarios

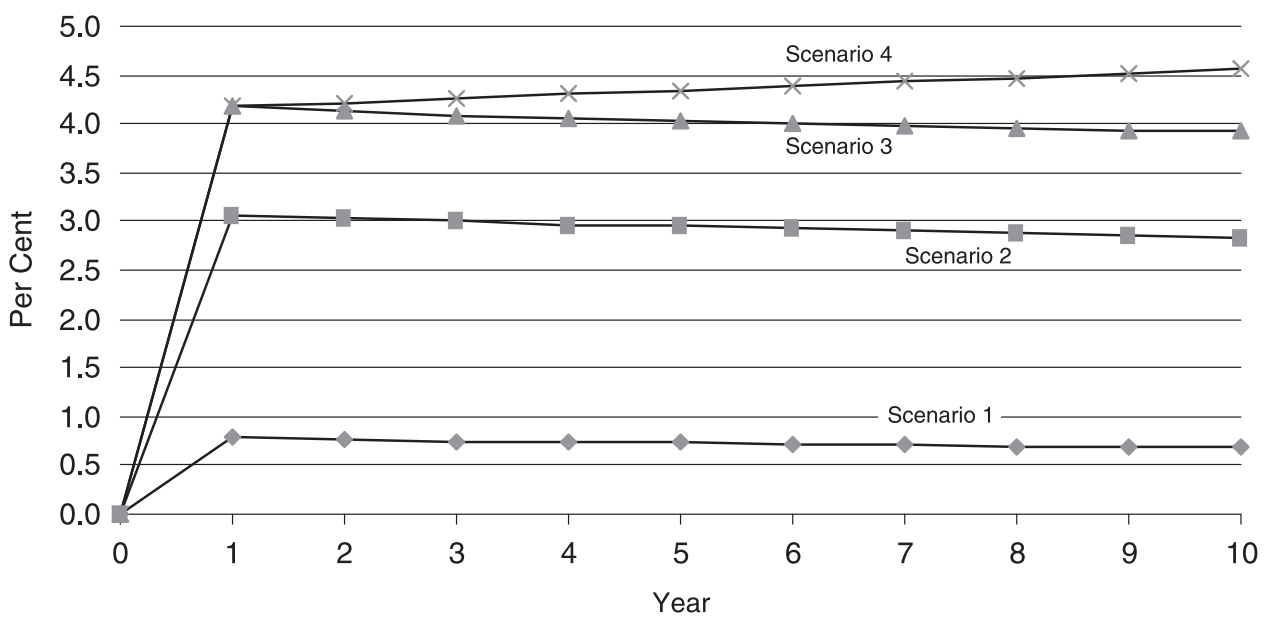

FIGURE 8

Cumulative Effect on Urban Surplus Labour: Comparison of Scenarios

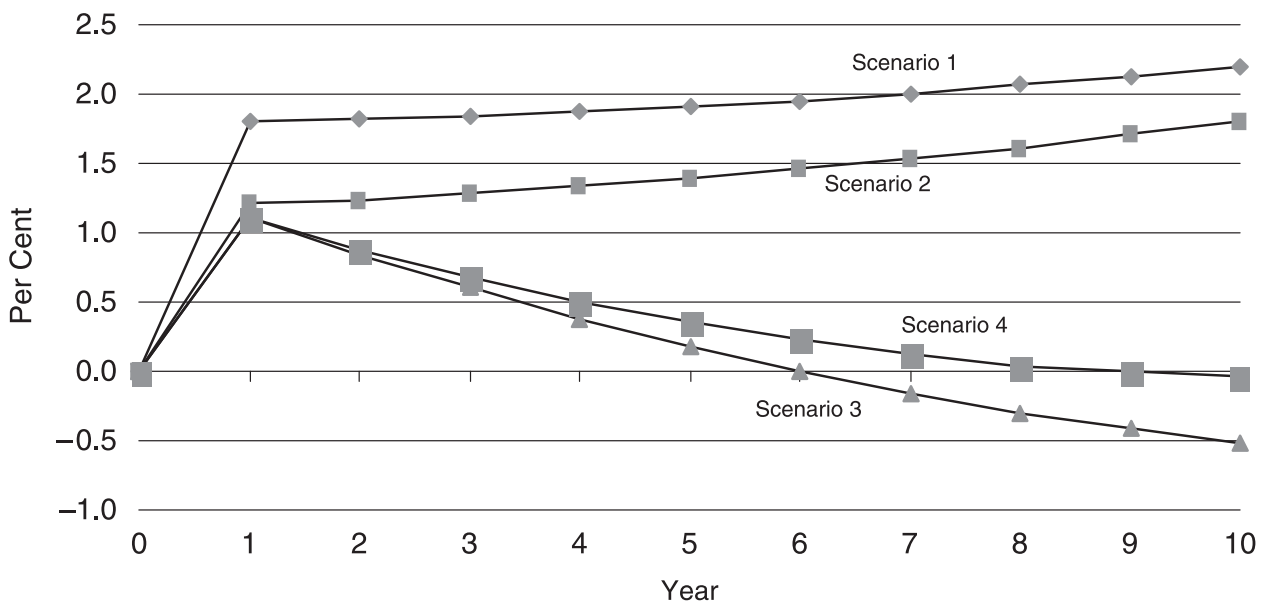

One notable result here is that despite the replacement of the sugar subsidy by other forms of aid, there is initially a considerable rise in urban surplus labour under Scenarios 2-4. This occurs because the sugar industry is labour intensive and more labour intensive than those industries which benefit from the alternative aid regimes of Scenarios 2-4. However, in the cases of Scenarios 3 and 4, the rise in surplus labour is negated within a relatively short period of time, and in the longer term the reforms under these scenarios will generate benefits in surplus labour (Figure 8). 
FIGURE 9

Cumulative Aggregate Employment Effects After 10 Years, Comparison of Scenarios

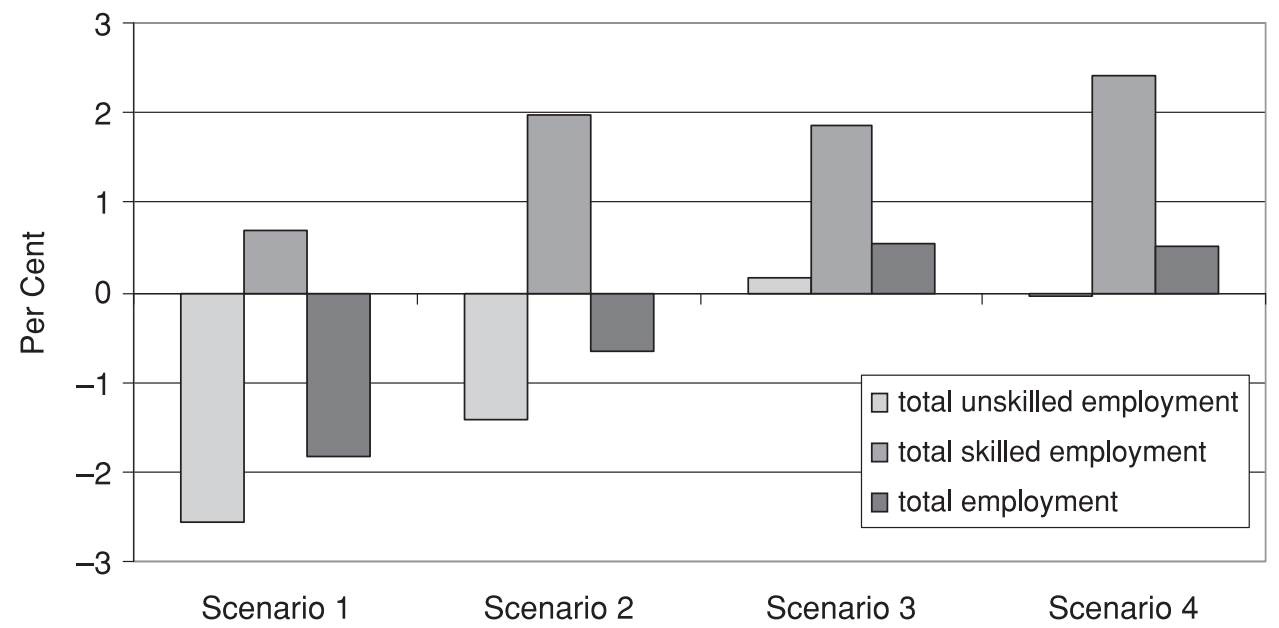

Total employment in Fiji is predicted to rise 0.5 per cent after 10 years for Scenarios 3 and 4 (Figure 9). Most of this is generated from a rise in skilled employment as production in Fiji shifts from the unskilled intensive sugar industry to industries less intensive in their use of unskilled labour. Total unskilled employment in Scenario 3 rises 0.2 per cent after 10 years and in Scenario 4 falls 0.1. In contrast, total skilled employment rises 1.9 per cent and 2.4 per cent. These results add weight to the argument that an important part of the reform process should be to enhance education and training to better prepare people for jobs with higher skill requirements.

\section{CONCLUSIONS}

Alternative forms of aid can deliver to ACP economies much greater benefits than are currently provided under the scheme of sugar preferences. The quantitative experiments using Fiji as a case study demonstrate the significant economic gains and higher growth paths that can be achieved by switching aid from sugar preferences to infrastructure development. The assumptions used in the quantitative analysis are conservative so the gains that can be achieved are likely to exceed those reported in the analysis.

Areas for which aid will deliver the greatest returns will vary from country to country according to their current progress in social and economic development. Significant gains in the growth paths of productivity and private sector investment can be achieved not only through infrastructure investment, but via a number of alternative policy directions. This may include investing in health, education, 


\section{THEODORE LEVANTIS, FRANK JOTZO AND VIVEK TULPULÉ}

governance and public institutions, especially legal institutions. In the case of Fiji, for example, resources committed to labour market reform would provide important gains. Under current labour market conditions, reduced flexibility of production brought about by labour market rigidities reduces the scope for non-sugar industries to capitalise on improved conditions - including real exchange rate depreciation - thereby reducing the potential benefits of the alternative policies.

One final point: the quantitative component of this study does not pay attention to equity considerations. To a large degree, equity considerations are the subjective domain of the community and of government. However, what can be said is that the gains that can be made by pursuing alternative policy frameworks are able to be redirected to those groups that lose out from policy change so that all in the community are better off.

\section{REFERENCES}

Aschauer, D. A. (1989), 'Does Public Capital Crowd Out Private Capital?', Journal of Monetary Economics, 24, 2, 171-88.

Bilal, S. and K. Van Hove (2002), An Overview of ACP-EU Negotiations: Issues and Timeframe (Maastricht: European Centre for Development Policy Management).

Bureau, J.-C., H. Guyomard and V. Requillart (2001), 'Inefficiencies in the European Sugar Regime', Journal of Policy Modeling, 23, 6, 659-67.

Court of Auditors (2001), 'Special Report No. 20/2000 Concerning the Management of the Common Organisation of the Market for Sugar', Official Journal of the European Communities, 44 (15 February).

Démurger, S. (2001), 'Infrastructure Development and Economic Growth: An Explanation for Regional Disparities in China?', Journal of Comparative Economics, 29, 1, 95-117.

Easterly, W. and S. Rebelo (1993), 'Fiscal Policy and Economic Growth', Journal of Monetary Economics, 32, 3, 417-58.

European Commission (2002), 'New Strategy for Partnerships with African, Caribbean and Pacific Countries', Press release (9 April, Brussels).

Gupta, S., B. J. Clements, E. Baldacci and C. Mulas-Granados (2002), 'Expenditure Composition, Fiscal Adjustment, and Growth in Low-income Countries', IMF Working Paper No. 02/77 (Washington, DC)

Harris, S., K. Parris, C. Ritson and E. Tollens (1978), 'The Re-negotiation of the ACP-EEC Convention of Lomé, with Special Reference to Agricultural Products' (London: Commonwealth Secretariat).

Herrmann, R. and D. Weiss (1995), 'A Welfare Analysis of the EC-ACP Sugar Protocol', Journal of Development Studies, 31, 6, 918-33.

IMF (2002), Fiji: Selected Issues and Statistical Appendix (IMF Asia and Pacific Department).

Lall, P., A. M. Featherstone and D. W. Norman (2000), 'Productive Efficiency and Growth Policies for the Caribbean', Applied Economics, 32, 11, 1483-93.

Licht, F. O. (2002), International Sugar and Sweetener Report (various issues).

Oxfam (2002), ‘The Great EU Sugar Scam: How Europe's Sugar Regime is Devastating Livelihoods in the Developing World', Oxfam Briefing Paper No. 27.

Page, S. and A. Hewitt (2002), 'The New European Trade Preferences: Does "Everything But Arms" (EBA) Help the Poor?', Development Policy Review, 20, 1, 91-102.

Sanchez-Robles, B. (1998), 'Infrastructure Investment and Growth: Some Empirical Evidence', Contemporary Economic Policy, 26, 1, 98-108. 
Sheales, T., S. Gordon, A. Hafi and C. Toyne (1999), 'Sugar: International Policies Affecting Market Expansion', ABARE Research Report 99.14 (Canberra).

Topp, V. (2001), 'Trade Preferences: Are They Helpful in Advancing Economic Development in Poor Countries?', ABARE Report TP01 (Canberra).

Wang, E. C. (2002), 'Public Infrastructure and Economic Growth: A New Approach Applied to East Asian Economies', Journal of Policy Modeling, 24, 5, 411-35.

World Bank (1994), World Development Report 1994: Infrastructure for Development (Washington, DC).

World Bank (2002a), World Development Report 2002: Building Institutions for Markets (Washington, DC).

World Bank (2002b), World Development Indicators (Washington, DC).

WTO (2002), Notification by the European Communities on Export Subsidy Commitments for the Marketing Year 2000/2001 (Geneva: Document G/AG/N/EEC/36). 